\title{
Using Scholarly Big Data in Assessing Contribution of National Expertise to Climate Change Knowledge; Case Study: Egypt
}

\author{
Mahmoud A. Hassaan \\ Alexandria Research Center for Adaptation to Climate Change (ARCA), Institute of Graduate Studies and Research, Alexandria \\ University, Alexandria, Egypt \\ Email: mhassaan@alexu.edu.eg
}

How to cite this paper: Hassaan, M.A. (2018) Using Scholarly Big Data in Assessing Contribution of National Expertise to Climate Change Knowledge; Case Study: Egypt. Journal of Data Analysis and Information Processing, 6, 67-78. https://doi.org/10.4236/jdaip.2018.63005

Received: May 13, 2018

Accepted: July 1, 2018

Published: July 4, 2018

Copyright $\odot 2018$ by author and Scientific Research Publishing Inc. This work is licensed under the Creative Commons Attribution International License (CC BY 4.0).

http://creativecommons.org/licenses/by/4.0/

\begin{abstract}
Scholarly documents are generated on daily basis in varied formats. Google Scholar is one of the most popular open access web search engines that involves metadata of massive volume of varied scholarly literature that is generated autonomously and in high velocity. This means that Google Scholar data should be considered from Big Data perspective. Despite a growing literature on climate change in Egypt, there has never been a comprehensive survey of the literature produced by Egyptian researchers in the field. The paper in hand is intended to study and assess existing literature on climate change undertaken by Egyptian researchers available at Google Scholar. For this purpose, systematic mapping approach was utilized in this work. It was found that there were 189 research papers undertaken by Egyptian researchers on various climate change topics over a ten years period 2007-2017. Yet, about $33 \%$ of the produced literature was found to have been published in less reputable publications. Research papers undertaken by Egyptian researchers were found to be on the increase during this period. It was also found that the majority of the published research focused on specific topics such as agriculture and sea level rise, while disregarding a number of vital topics in the case of Egypt such as tourism, health and energy.
\end{abstract}

\section{Keywords}

Big Data, Google Scholar, Egypt, Climate Change

\section{Introduction}

Big data is an ambiguous term that generally refers to massive unstructured volume of datasets available at autonomous and heterogeneous sources, which get 
updated within a fraction of a second (Singh et al., 2015) [1]. Big data can usually be distinguished through three main features: volume, velocity and variety (Hilbert, 2016; Taylor et al., 2014) [2] [3]. The emergence of big data was motivated by recent unprecedented development of information and communication technologies and associated shift towards digital production and dissemination of information (Tu et al., 2017) [4]. For example, increasing number of online search engines, social media and mobile phone use, represents potential sources of big data.

Nowadays, scholarly documents are generated daily in varied formats ranging from theses, technical reports, project proposals, working papers, conference papers, book chapters, to original research papers and review articles (Khan et al., 2017) [5]. Currently, there are a number of open access web search engines that index the full text or metadata of large number of scholarly literature covering a wide range of disciplines. Google Scholar is, in this respect, considered to be one of the most popular such open access web search engines. It was estimated that Google Scholar's database contains about 160 - 165 million documents (Orduna-Malea et al., 2015) [6]. Other estimates suggest that Google Scholar covers about $87 \%$ of the total number of scholarly documents published in English on the web (Khabsa and Giles, 2014) [7]. Due to massive volume of the generated scholarly documents (Khan et al., 2017) [5], their variety and velocity of generation, Google Scholar data should be considered from the Big data perspective.

Egypt is one of the most vulnerable countries to climate change associated risks that are expected to affect adversely all sectors in Egypt (Smith et al., 2013) [8]. Owing to the significance of climate change impacts, researchers affiliated to Egyptian universities and various research institutions have studied frequently climate change associated risks and their implications (Hassaan and Abdrabo, 2014) [9]. Despite a relatively growing literature on climate change in Egypt, no attempt was made to comprehensively survey the literature in the field of climate change produced by Egyptian researchers, whether to identify existing gaps and/or support the development of a research agenda in this respect.

The working paper in hand is intended to evaluate existing literature on climate change undertaken by Egyptian researchers and is available at Google Scholar. For this purpose, systematic mapping approach was applied, which is highly recommended in such evaluations, as it enables thematic analysis and allows for the identification of gaps in the considered topic (Akoka et al., 2017) [10]. Such an evaluation can contribute to portraying past and current state of research on climate change and highlighting existing gaps in the literature and consequently identifying those areas of research that need to be considered in the future.

\section{Data and Methodology}

To evaluate literature on climate change undertaken by Egyptian researchers 
available in Google Scholar a methodology of six main steps was applied namely; identifying data frame, framing questions, developing search criteria, conduct search, screening scholarly records and finally classification and evaluation (Figure 1). Each of these steps is briefly discussed in the remaining part of this section.

The time frame of the intended evaluation had to be clearly defined. In this respect, the period extending between 2007 and 2017 was selected to undertake the evaluation. During this period IPCC $4^{\text {th }}$ Assessment Report (AR4) (IPCC, 2007) [11] and IPCC 5th Assessment Report (AR5) (IPCC, 2014) [12] were issued in 2007 and 2013 respectively. The two reports provided most evidence on climate change and associated significant impacts on various aspects of human life. This, in turn, attracted more researchers to consider climate change topics.

Using the keywords "Egypt, Nile Delta, Red Sea", "Global warming" OR "greenhouse gases" OR "sea level rise" OR "inundation" OR "vulnerability" OR "adaptation" OR "mitigation", a number of searches for literature on climate change was undertaken using Google Scholar (Google, 2017) [14]. The searches, which covered the time period 2007-2017, were only applied to the research titles. Due to varied forms of scholarly documents existing in Google Scholar, there was a need to develop a set of screening criteria to restrict the search results to the scope of the evaluation and its time frame. Accordingly, it was decided, based on above discussion on IPCC reports, that the evaluation would consider only original research papers published by Egyptian researchers during the period 2007-2017.

Thereafter, these inclusion criteria were applied to the extracted scholarly

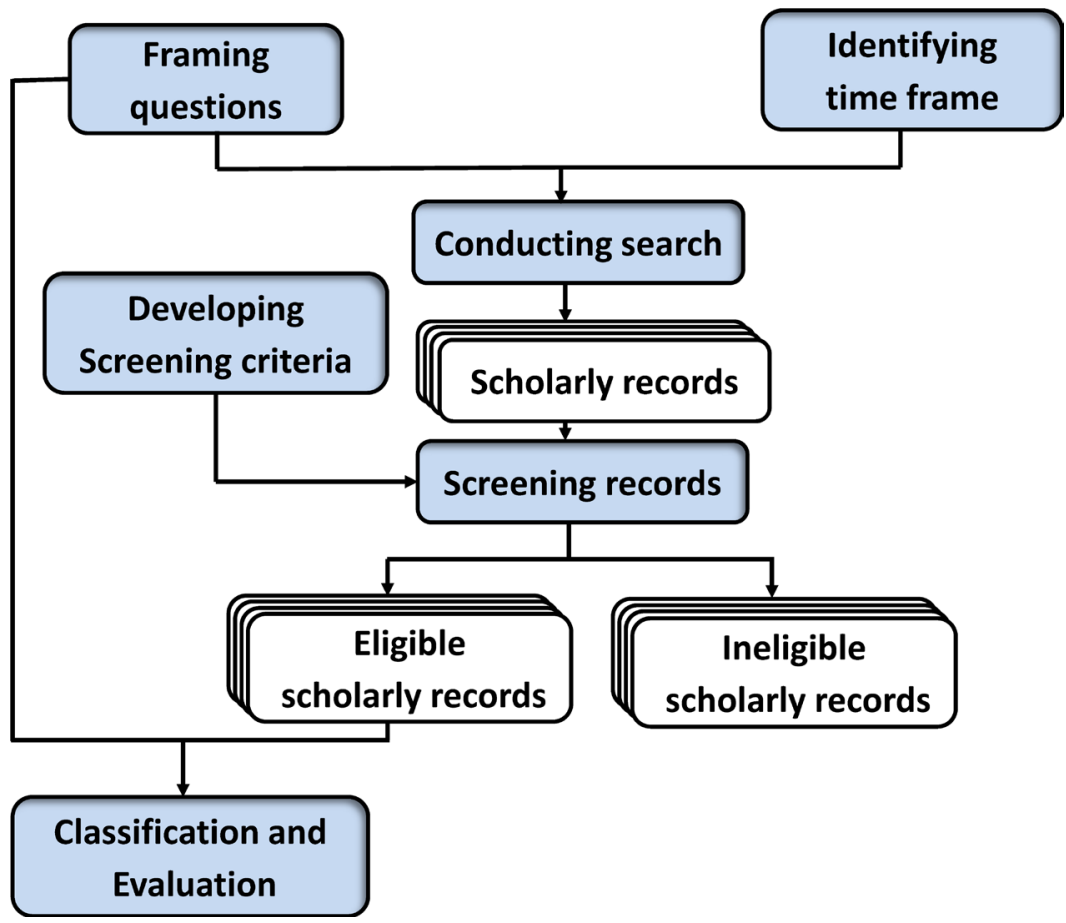

Figure 1. Methodology. Adopted from (Akoka et al., 2017; Cohen, 2017) [10] [13]. 
documents. As a result of screening process, all forms of scholarly documents other than original research papers (e.g. theses, book chapters, reports and working papers) were excluded. Similarly, all original research papers that were undertaken by non-Egyptian researches were, also, excluded.

This is mainly due to research papers published in conferences proceedings have usually less reputation compared to journal articles (Derntl, 2014; González-Albo and Bordons, 2011) [15] [16]. Similarly, articles published in international journals have higher impact factors relative to local research journals.

Finally, all eligible scholarly documents were classified and analyzed in the light of the questions framed-earlier to identify the number of produced research papers, trend and forms of publications, and the main investigated themes.

\section{Results and Discussion}

As a result of searches conducted on Google Scholar, 268 scholarly documents on climate change topics were extracted. Screening these documents based on inclusion criteria, 79 documents were excluded as they were not original research papers or undertaken by non-Egyptian researchers. This means that there are 189 research papers on climate change topics undertaken by Egyptian researchers during the period 2007-2017 (Table 1).

In terms of publication form, major proportions of the produced research papers (67\%) were published in peer reviewed international journals, $27 \%$ were presented and published in conference proceedings. Meanwhile, only $6 \%$ of these research papers were published in national research journals (Figure 2).

Table 1. Number of literature on climate change undertaken by Egyptian researchers during the period 2007-2017.

\begin{tabular}{ccccc}
\hline Year & Conferences Proceedings & National Journals & International Journals & Total \\
\hline 2007 & 7 & 2 & 1 & 10 \\
2008 & 3 & 0 & 0 & 3 \\
2009 & 5 & 0 & 5 & 10 \\
2010 & 3 & 1 & 10 & 14 \\
2011 & 5 & 0 & 3 & 8 \\
2012 & 6 & 0 & 7 & 13 \\
2013 & 6 & 2 & 21 & 29 \\
2014 & 2 & 1 & 22 & 25 \\
2015 & 4 & 3 & 20 & 27 \\
2016 & 7 & 1 & 21 & 29 \\
2017 & 3 & 1 & 17 & 21 \\
Total & 51 & 11 & 127 & 189 \\
\hline
\end{tabular}




\subsection{Trend Analysis}

Despite that the number of published articles fluctuated over the period 2007-2017, a trend was found as the number of articles increased from 10 articles in 2007 to 29 in 2013 and 2016. Generally, it was found that the number of published articles over the period 2007-2017 increased steadily. The average trend formula indicates that the number of published article increased by 2.3 articles annually on average (Figure 3 ).

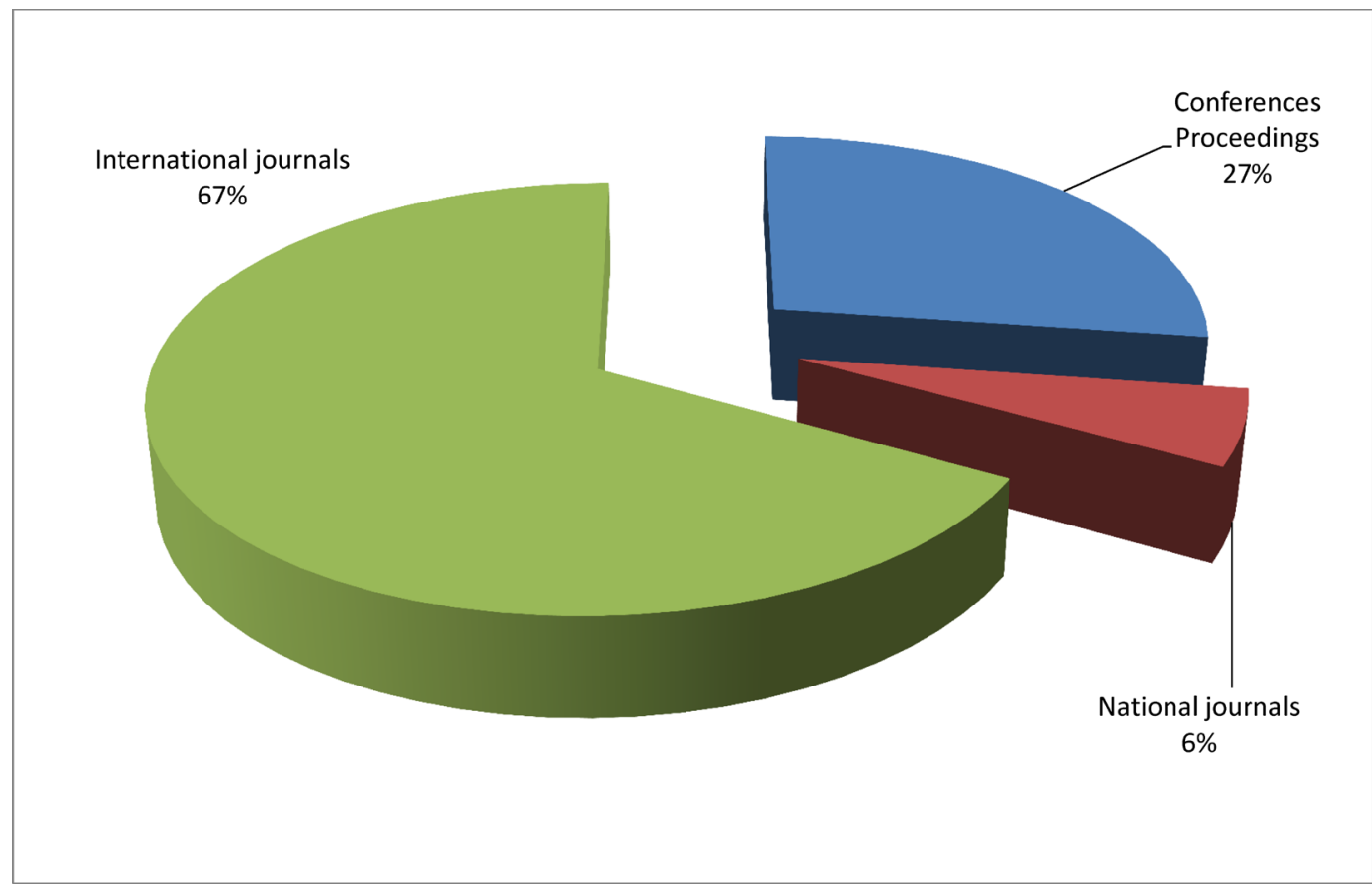

Figure 2. Relative distribution of research papers on climate change topics according to publication forms.

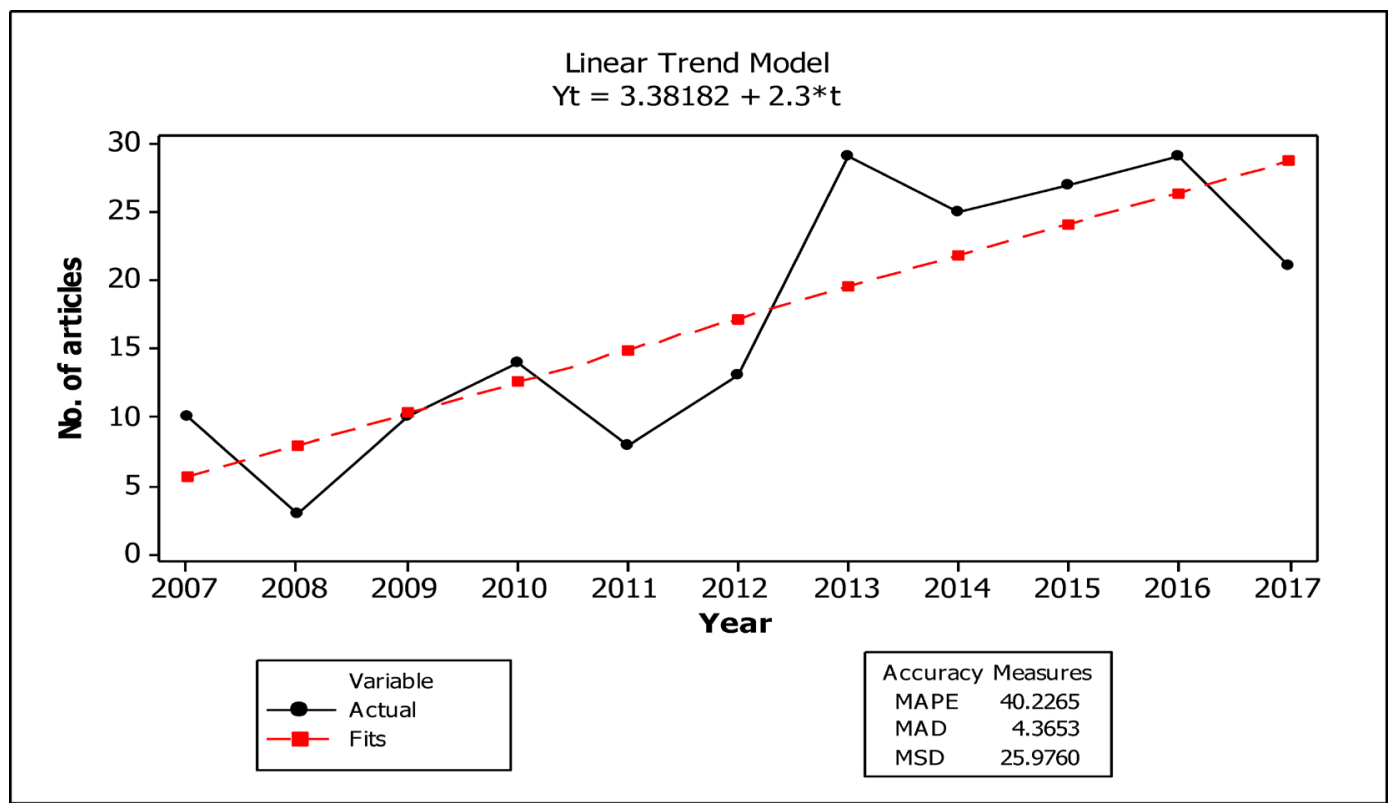

Figure 3. Annual evolution of published literature over the period 2007-2017. 
Looking into different forms of publication, it was found that each had its own trend. For instance, it was found that the proportion of research papers published in peer-reviewed international journals has increased from $10 \%$ in to $81 \%$ of total research papers in 2007 and 2017 respectively. By contrast, the share of research papers published in conference proceedings decreased notably from $70 \%$ to $14 \%$ of the total research papers published annually during this period. Similarly, the share of papers published in national research journals decreased from $20 \%$ to $5 \%$ with minor proportion of the total published research papers during the same period (Figure 4).

Such a trend of increasing proportions of research papers published in peer-reviewed international journals and decreasing papers presented in conferences with stagnant minor proportions of research paper published locally could reflect a general improvement in the quality of the produced literature over time.

\subsection{Thematic Analysis}

The research papers undertaken by Egyptian researches on climate change during the period 2007-2017, considered a wide range of themes, with agriculture sector and food security coming first with a combined $29.6 \%$ of the total literature. This was followed by sea level rise, water resources, Global warming and urban areas with $22.8 \%, 7.4 \%, 6.9 \%$ and $6.3 \%$ of the total research papers, respectively. This means that about $75 \%$ of the produced literature dealt with only

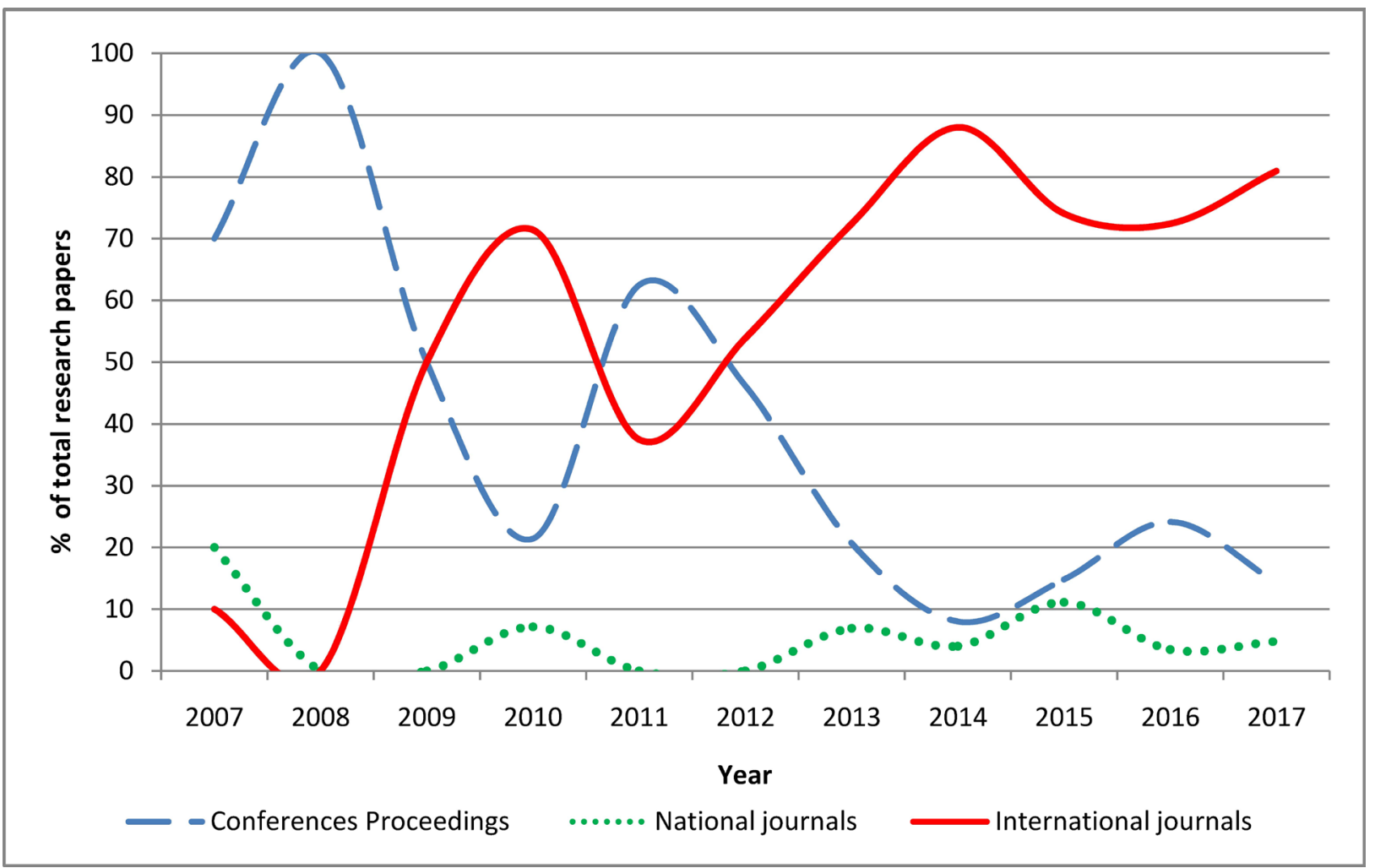

Figure 4. Trends of research papers proportions published in different forms. 
five themes (Figure 5).

Also, it was noticed that some important topics in climate change arena, such as energy, health, tourism and antiquities, awareness, and environment, received less attention. For example, only 19 research papers considered these themes together, which accounted for about $10 \%$ of the total number of research papers published during the period 2007-2017 (Table 2).

It should be noted that despite the large proportion of research papers in the field of agriculture and food security, about $44.6 \%$ of these articles were published in either conference proceedings or in local research journals. Similarly, $66.7 \%$ of the total articles on urban areas were published in conference proceedings. This could reflect a low reputation of the literature produced in these two fields (Figure 6).

Meanwhile, although limited number of articles on Energy, environment, perception and awareness and tourism and antiquities themes, they totally were published in international journals, which reflects generally higher quality of literature.

\subsection{Contributing Affiliations}

Egypt has a considerable research system that consists of 25 and 29 government and private universities, respectively. There are also a large number of national thematic research centers affiliated with different ministries, such as National Research Center and National Institute of Oceanography and Fisheries, affiliated

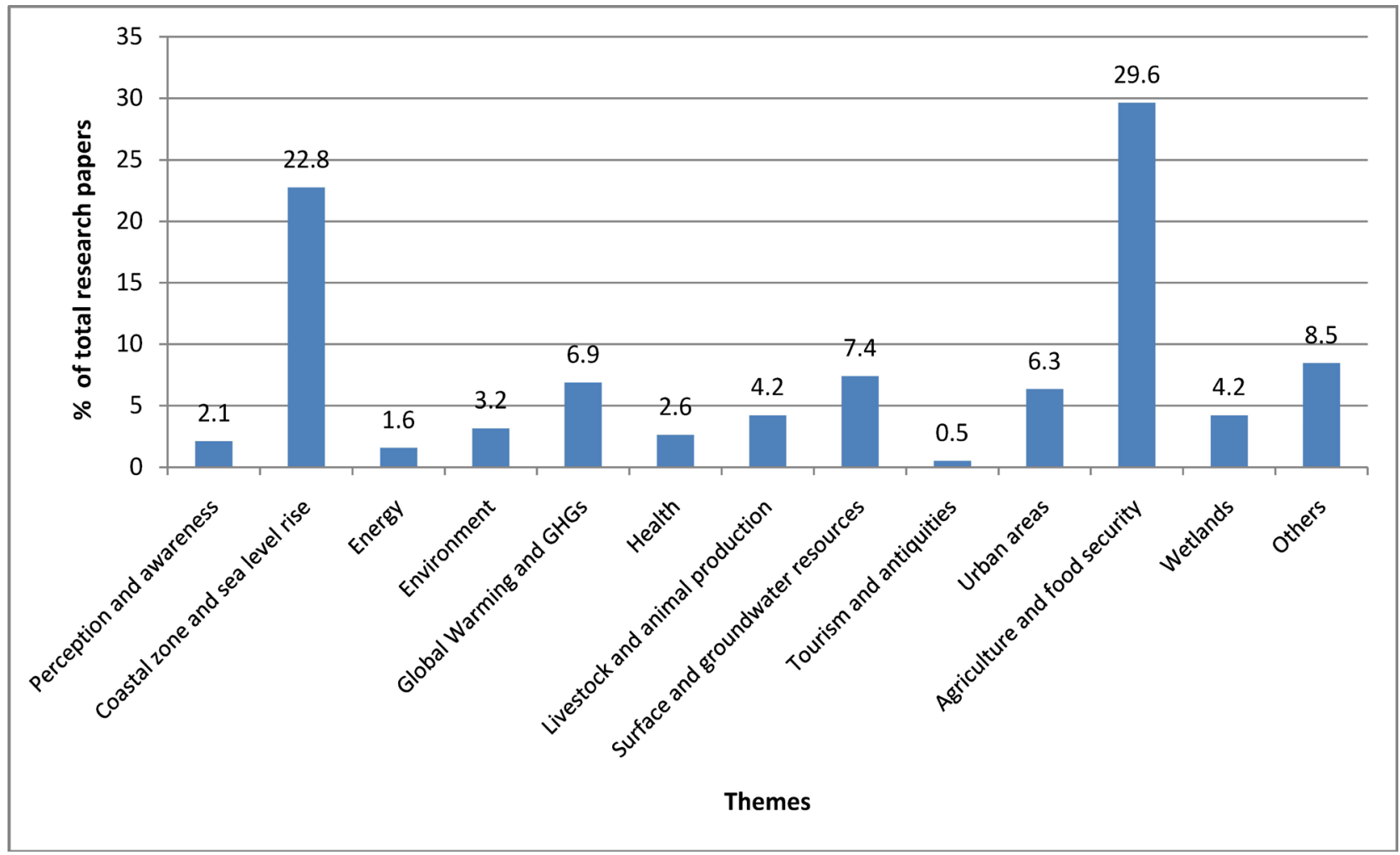

Figure 5. Proportions of literature per most frequent investigated topics. 
Table 2. Number and proportions of literature per different themes.

\begin{tabular}{cccccc}
\hline Themes & $\begin{array}{c}\text { Conferences } \\
\text { Proceedings }\end{array}$ & $\begin{array}{c}\text { National } \\
\text { Journals }\end{array}$ & $\begin{array}{c}\text { International } \\
\text { Journals }\end{array}$ & Total & $\%$ \\
\hline Perception and awareness & 0 & 0 & 4 & 4 & 2.1 \\
Sea level rise & 13 & 1 & 29 & 43 & 22.8 \\
Energy & 0 & 0 & 3 & 3 & 1.6 \\
Environment & 0 & 0 & 6 & 6 & 3.2 \\
Global Warming and GHGs & 1 & 0 & 12 & 13 & 6.9 \\
Health & 0 & 1 & 4 & 5 & 2.6 \\
Livestock and animal production & 0 & 2 & 6 & 8 & 4.2 \\
Surface and groundwater resources & 4 & 0 & 10 & 14 & 7.4 \\
Tourism and antiquities & 0 & 0 & 1 & 1 & 0.5 \\
Urban areas & 8 & 0 & 4 & 12 & 6.3 \\
Agriculture and food security & 18 & 7 & 31 & 56 & 29.6 \\
Wetlands & 3 & 0 & 5 & 8 & 4.2 \\
Others & 4 & 0 & 13 & 16 & 8.5 \\
Total & 51 & 11 & 128 & 189 & 100 \\
\hline
\end{tabular}

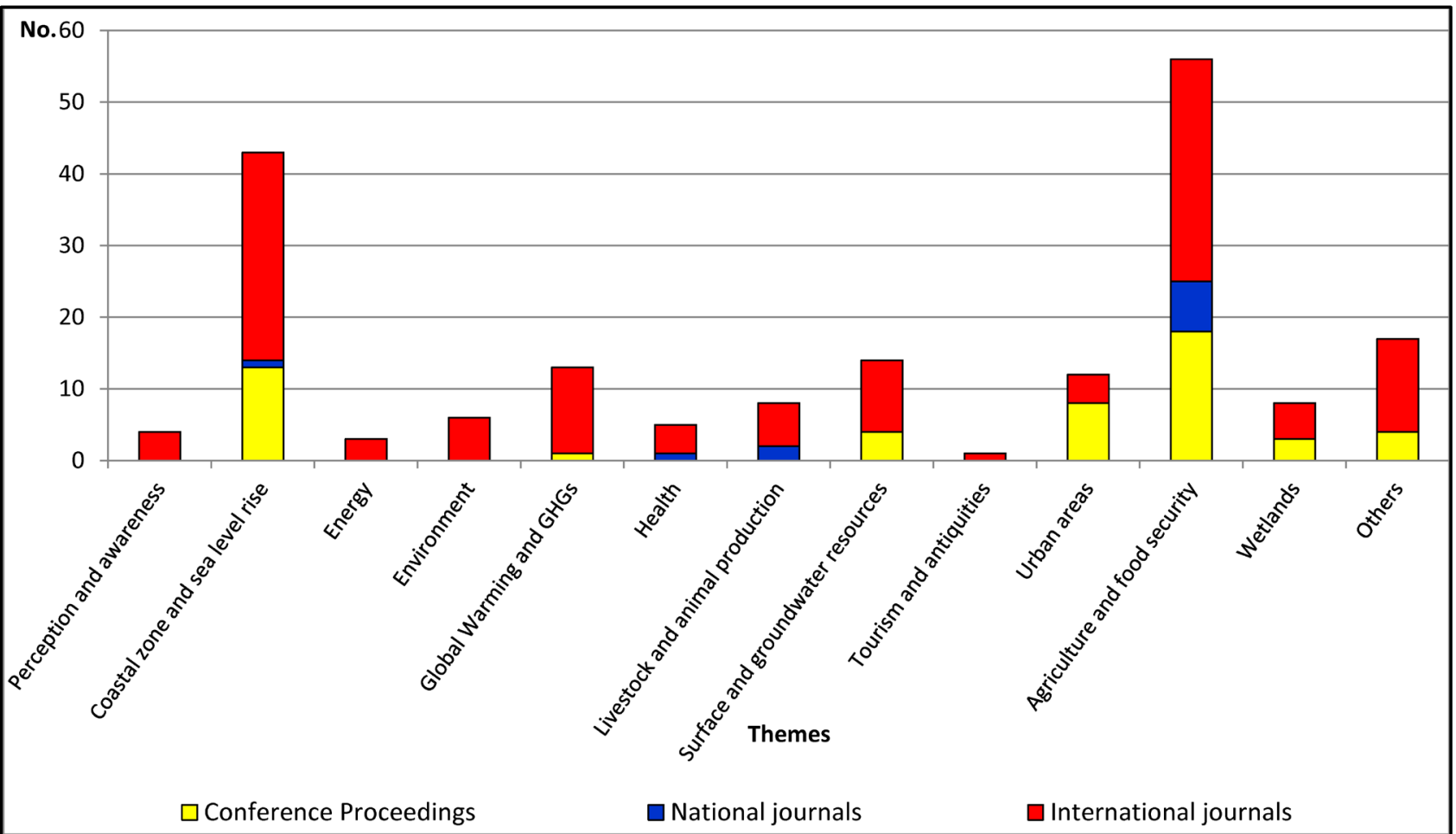

Figure 6. Number of different form of publications per most frequent investigated topics.

with the National Academy of Science-Ministry of Higher Education, National Water Research Center affiliated with the Ministry of Water Resources and Irrigation and National Agricultural Research Center affiliated with the Ministry of 
Agriculture, (SCU, 2012) [17]. This research system involves large number of researchers in wide range of disciplines. For instance, it was estimated that government universities employ more than 77,000 academics (Hassaan and Abdrabo, 2014) [9].

Identification of the contribution of various affiliations to the published literature was classified according to the affiliation of the first author. In this respect, it was found that $45 \%$ of the total literatures were carried out by researchers affiliated with universities (Figure 7). Meanwhile, $47 \%$ of the total scholar documents were undertaken by researchers affiliated to national research centers, with major contribution by Agriculture Research Center and National Water Research with a combined contribution of $38 \%$ of the total literature produced during the period 2007-2017.

It is worth stressing, again, that considerable proportions of the undertaken research papers had low quality and less reputation. For example, this proportion was $41.3 \%$ of the total research papers in the case of National Agricultural Research Center and $33.7 \%$ in the case of universities were published either in conference proceedings or in national journals.

Such low quality of produced research work can be explained by the wide range of challenges these universities and research institutes are suffering such as limited financial resources and mismatch between the produced research and

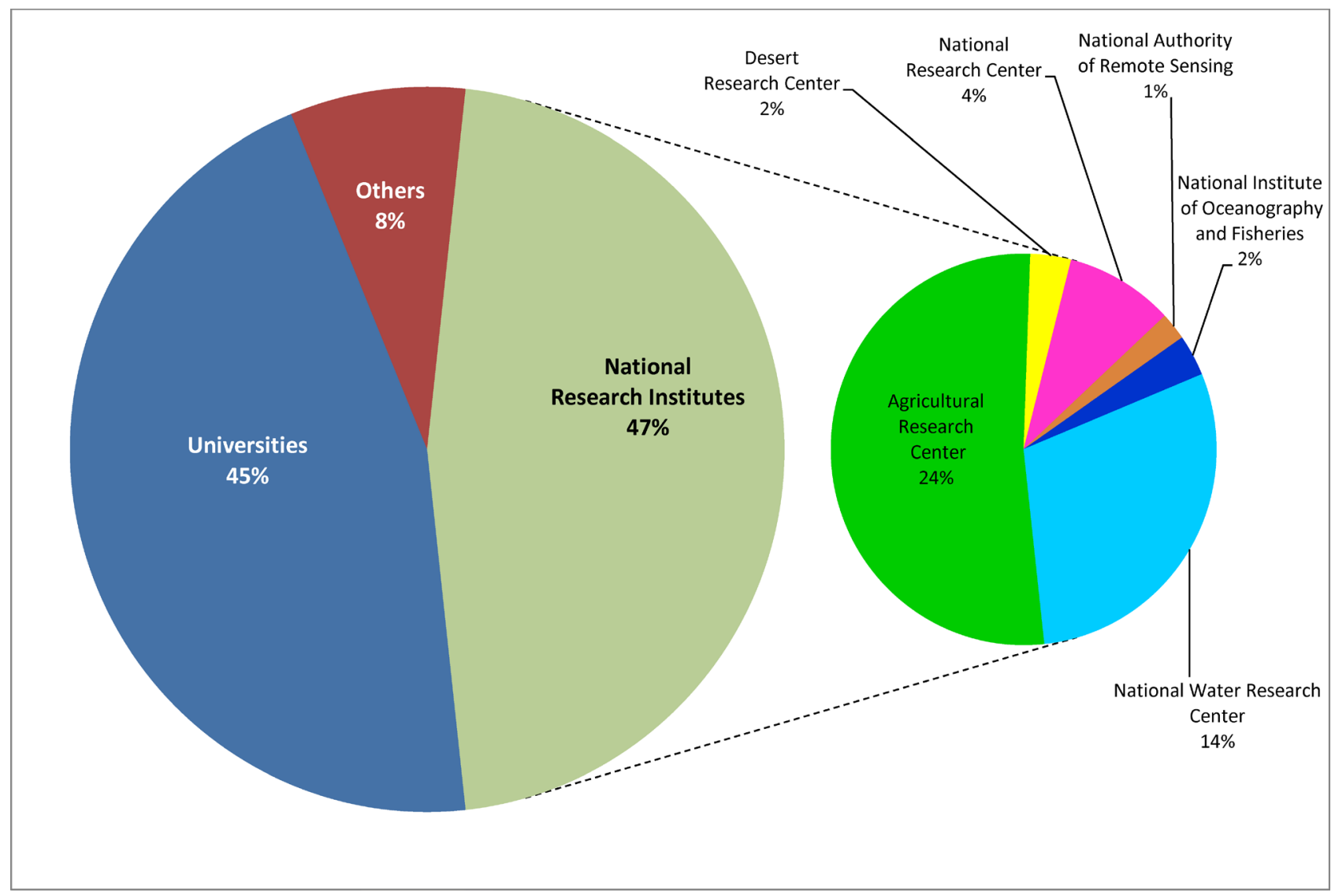

Figure 7. Literature produced per affiliation during the period 2007-2017. 
the national innovation system (El Baradei and El Baradei, 2004; Rached and Craissati, 2000) [18] [19].

As for different universities contribution, it was found that among the 54 Egyptian universities, 21 universities only contributed to the literature on climate change topics including two private universities. In this context, Alexandria University and Zagazig University came in the first and second places with contribution of $14 \%$ and $10.5 \%$, respectively, of the total literature published by researchers affiliated to universities (Figure 8).

\section{Conclusions}

Despite increasing trend in the number of research papers undertaken by Egyptian researchers on various themes related to climate change during the period 2007-2017, some themes were not covered and thus need additional attention. In this context, tourism and antiquities, health, energy and environment are the most disregarded themes. The analysis revealed that considerable proportions of the published research papers have less reputation as they were published in conference proceedings and national research journals. Therefore, the published literatures are expected to have limited impact and minimum policy implications. This highlights the need for improving quality of the produced research works to increase the contribution of research in enhancing resilience of various sectors to climate change.

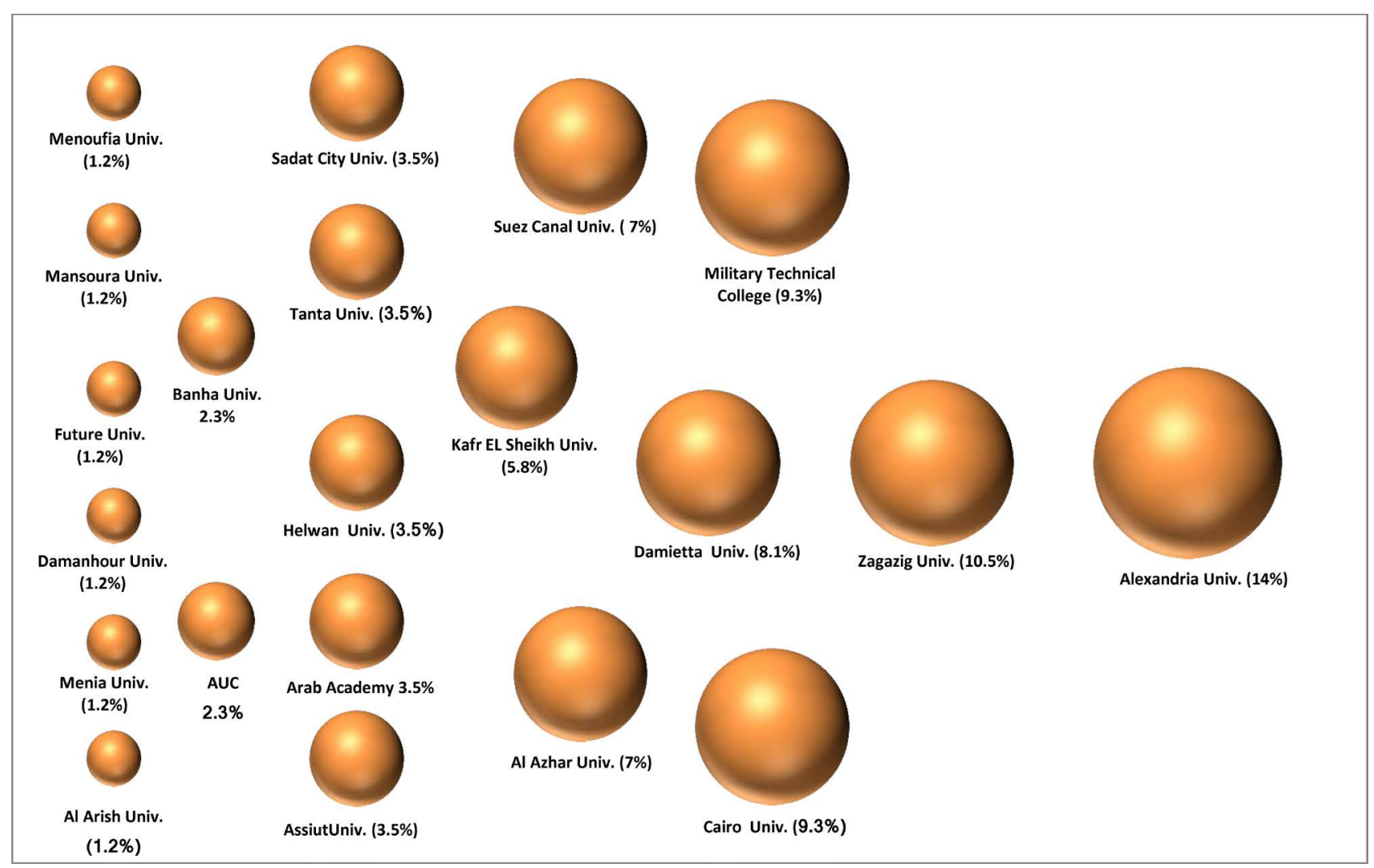

Figure 8. Relative contribution of various universities to literature on climate change. 
Also, there is a need to activate the role of universities in the generation of knowledge relevant to climate change and motivate their affiliated researchers to consider climate change topics and undertake high quality research work. This can be attained by providing more financial resources for research activities and capacity building activities. Moreover, to reduce redundancy and duplication, there's a need to develop more systemic approach to research on climate change in Egypt.

Finally, more accurate assessment of contribution of various affiliations requires considering varied human resources of these affiliations. Thus, the published literature by each affiliation needs to be related to the number of researchers of this affiliation.

\section{Acknowledgements}

This research work is part of a research project sponsored by the IDRC-Canada for establishing Alexandria Research Center for Adaptation to Climate Change (ARCA) at the Alexandria University, Egypt. The contribution of ARCA, in its life time since 2011, accounted for about $5 \%$ of the total literature on climate change undertaken by Egyptian researchers and $10 \%$ of the literature undertaken by researchers affiliated with Egyptian universities since 2007.

\section{References}

[1] Singh, S., Firdaus, T. and Sharma, A.K. (2015) Due to Massive Volume of the Generated Scholarly Documents, Their Variety and Velocity of Generation. International Journal of Engineering Development and Research, 3, 135-143.

[2] Hilbert, M. (2016) Big Data for Development: A Review of Promises and Challenges. Development Policy Review, 34, 135-174. https://doi.org/10.1111/dpr.12142

[3] Taylor, L., Cowls, J., Schroeder, R. and Meyer, E.T. (2014) Big Data and Positive Change in the Developing World. Policy \& Internet, 6, 418-444. https://doi.org/10.1002/1944-2866.POI378

[4] Tu, C.M., He, X., Shuai, Z.K. and Jiang, F. (2017) Big Data Issues in Smart Grid-A Review. Renewable and Sustainable Energy Reviews, 79, 1099-1107. https://doi.org/10.1016/j.rser.2017.05.134

[5] Khan, S., Liu, X., Shakil, K.A. and Alam, M. (2017) A Survey on Scholarly Data: From Big Data Perspective. Information Processing \& Management, 53, 923-944. https://doi.org/10.1016/j.ipm.2017.03.006

[6] Orduna-Malea, E., Ayllón, J.M., Martín-Martín, A. and López-Cózar, E.D. (2015) Methods for Estimating the Size of Google Scholar. Scientometrics, 104, 931-949. https://doi.org/10.1007/s11192-015-1614-6

[7] Khabsa, M. and Giles, C.L. (2014) The Number of Scholarly Documents on the Public Web. PLoS One, 9, e93949. https://doi.org/10.1371/journal.pone.0093949

[8] Smith, J, Deck, L., McCarl, B., Kirshen, P., Malley, J. and Abdrabo, M. (2013) Potential Impacts of Climate Change on the Egyptian Economy, A Report Prepared for the United Nations Development Program (UNDP). Cairo, Egypt.

[9] Hassaan, M.A. and Abdrabo, M.A. (2014) Stakeholder Analysis: Nile Delta and Climate Change. (ARCA) Alexandria Research Center for Adaptation to Climate Change, Alexandria. 
[10] Akoka, J., Comyn-Wattiau, I. and Laoufi, N. (2017) Research on Big Data-A Systematic Mapping Study. Computer Standards \& Interfaces, 54, 105-115. https://doi.org/10.1016/j.csi.2017.01.004

[11] IPCC (2007) IClimate Change 2007: Synthesis Report. Contribution of Working Groups I, II and III to the Fourth Assessment Report of the Intergovernmental Panel on Climate Change $\mathrm{x}$, Geneva.

[12] IPCC (2014) Climate Change 2014: Synthesis Report. Contribution of Working Groups I, II and III to the Fifth Assessment Report of the Intergovernmental Panel on Climate Change, IPCC, Geneva.

[13] Cohen, M. (2017) A Systematic Review of Urban Sustainability Assessment Literature. Sustainability, 9, 2048. https://doi.org/10.3390/su9112048

[14] Google (2017) Google Scholar. https://scholar.google.com/schhp?hl=en

[15] Derntl, M. (2014) Basics of Research Paper Writing and Publishing. International Journal of Technology Enhanced Learning, 6, 105-123. https://doi.org/10.1504/IJTEL.2014.066856

[16] González-Albo, B. and María, B. (2011) Articles vs. Proceedings Papers: Do They Differ in Research Relevance and Impact? A Case Study in the Library and Information Science Field. Journal of Informetrics, 5, 369-381. https://doi.org/10.1016/j.joi.2011.01.011

[17] SCU (2012) Supreme Council of Universities. Supreme Council of Universities. http://scu.eg/pages/public_universities

[18] El Baradei, M. and El Baradei, L. (2004) Needs Assessment of the Education Sector in Egypt (ZEF). Center for Development Research, Bonn.

[19] Rached, E. and Craissati, D. (2000) Research for Development in the Middle East and North Africa. International Development Research Centre. 